\title{
Active Data Maps of Control Unit for Racing Motorcycle
}

\author{
Peter Bigoš ${ }^{1 *}$, Roman Tonhajzer ${ }^{2}$, Michal Puškár ${ }^{3}$, Melichar Kopas ${ }^{4}$ \\ 1,23,4 Department of Machine Design, Transport and Logistics Letná 9, 04001 Košice, Slovak Republic
}

\section{BIOGRAPHICAL NOTES}

prof. Ing. Peter Bigoš, CSc. is a university professor nominated in the branch of science "Transport and Handling Engineering". He is a head of the Department of Machine Design, Transport and Logistics at the Faculty of Mechanical Engineering, Technical University of Košice. He graduated at the Faculty of Mechanical Engineering of the former Technical College in Košice (1973). Dissertation thesis he defended in 1980 and in 1983 he was designated as a docent (associate professor). In 1991 he defended his inaugural dissertation at the Technical University of Košice. In the framework of his study stages he visited TU Miskolc, VH Dresden (1981), Polytechnika Rzeszowska (1983), Ruhr Universität Bochum (1989), Imperial College London (1993), TU Budapest (1997). He is a vice-chairman of the "Common professional commission for PhD.-study" in the branch of study "Transport Machines and Machinery" and he is a member of professional commission in the branch "Forensic Engineering", too. He is also member of several advisory boards of domestic and foreign professional journals, as well as he is a guarantor of international and domestic conferences about transport machines and logistics.

Ing. Roman Tonhajzer is a internal Phd. student at the Department of Machine Design, Transport and Logistics at the Faculty of Mechanical Engineering, Technical University of Košice. He graduated in 2012 with theme of his diploma thesis: Optimalization fuel maps and data of control unit for four stroke combustion engine. At present he dedicated to the research and development of piston combustion engines, single-track transport means and application research for racing motorcycles.

Ing. Michal Puškár, PhD. is a researcher at the Department of Machine Design, Transport and Logistics at the Faculty of Mechanical Engineering, Technical University of Košice. He graduated at the mentioned Department in 2005 and the PhD.-degree received in 2008 with theme of his dissertation thesis: Rising of Power Parameters of Single-Track Transport Means. His current fields of research interest are single-track transport means, piston combustion engines and increasing of their power output and reliability.

Ing. Melichar Kopas, PhD. is an assistant lecturer at the Department of Machine Design, Transport and Logistics at the Faculty of Mechanical Engineering, Technical University of Košice. He graduated at the Department of Transport and Handling Machines, which was a predecessor of the above-mentioned Department in 1988. The PhD.-degree he obtained with the dissertation thesis target on the theoretical and practical questions concerning the transport systems of bulk materials. His research activities are focused on the driving mechanisms and transmissions designed for the transport and handling machines or machineries as well as on the theory and construction of the mechanical conveyors for bulk solids. 


\section{KEY WORDS}

Checksum, Control Unit, Engine Management, Data Maps.

\section{ABSTRACT}

The current engine management of the four-stroke piston combustion engine require a continual distribution of the operational information. From this reason it is necessary to control the correctness of these data all the time. In order to realise this control process it should be applied the special software, which enables reading of the data fields and in this way it contributes to a faster and more correct distribution of the active measured values.

\section{Introduction}

The modern control units of the high-power spark-ignition engines are operating with different structures of the control algorithms and they are using also various related modification software products. The final power output of a four-stroke spark-ignition engine depends not only on a structure of the primary fuel maps during the tuning process, which is performed in the framework of the engine management, but it is necessary to take into consideration also the related data fields.

It is possible to adjust the engine management function by means of the data field editing process in the case of a high-power engine operation. A possibility to replace some of the electronic components, which are arranged in the printed circuit of the control unit, is only a very rare and specified occurrence. The most of serially produced motor-management systems that are specified for the racing motorbikes are designed with regard to the very demanding requirements concerning the speed and extent of data processing. These vehicles are not equipped with the special systems ensuring comfort and safety conditions because they are oriented towards the maximum power output parameters. The control algorithms of the control units are complicated and they are integrated mutually. Therefore it is not necessary to replace them by any specialized unoriginal control systems.

The more sophisticated possibility for editing of the data field requires an application of the specialised modification software, which is intended for the data fields with an active linkage to the sensors. In this paper there are presented results from application of the WinOLS 1.721 software.

\section{Experimental Section} 2.1 Data composition of engine management

The engine management control system is specified by a computer code, which determines real steps of the control program. The control unit microprocessor is using combinations of the elementary binary digits 0 and 1 . Due to managing of the individual activities the control software operates with numerical combinations in the hexadecimal form (Fig. 1). The individual data fields are determined by means of the data, which are recorded and saved in the above-mentioned forms. In order to modify the control program it is necessary to know relations between the hexadecimal system (hex.) and the decimal system (dec.). The control program ECU uses the format hex., which consists of 16 signs. There are applied the numerals from 0 to 9 together with the alphabetic letters from A to $\mathrm{F}[1]$.

The transformation process from the hexadecimal format to the decimal data by means of the editing software is important during adjustment of the basic data fields concerning the fuel injection, spark advance or input temperature data. A lot of the professional modification software products offer this transformation possibility with only very simple settings. If the basic view menu does not offer this transformation possibility, there is at disposal a calculator in the Windows operational system. In our case we applied the modification software WinOLS for the determination and editing of the data fields (Fig. 2). This software is well known in the branch of the automotive chip-tuning, however during the data reading in a suitably chosen format can be applied also various other kinds of the motorbike control units [2].

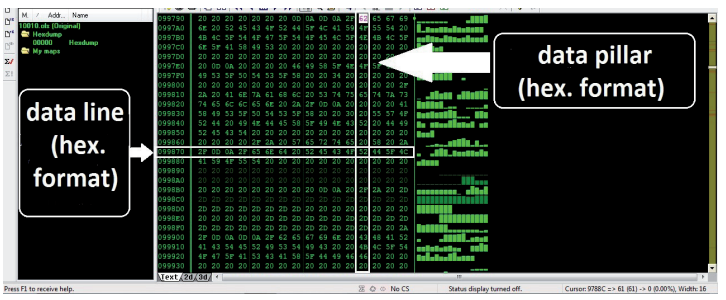

Fig. 1: Hexadecimal data format of motorcycle KAWASAKI KX450F.

The program WinOLS uses predominately the operational formats bin, hex, ols, olsx, s19, BdmToGo and vSpire. After correction it works with the formats HONDA E2P and KAWASAKI KSD. In order 
to display the operational data of the control unit the information structure is projected according to the various conceptions and that is why everyone producer can choose his own data structure regime [3].

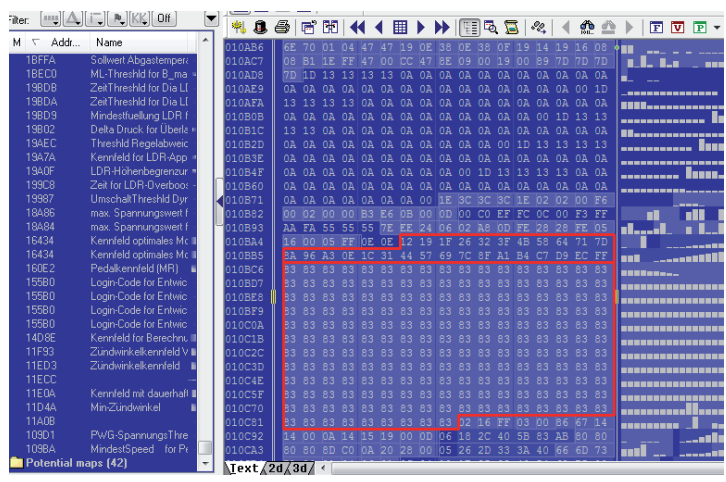

Fig. 2: Elementary data structure of racing motorcycle (WinOLS).

The most sophisticated modification programs enable an exact selection of the functional data fields from the memory EPROM as well as following correct modification of them. All the necessary information, which are unavoidable for a correct and fast reaction of the motor-management are addressed in such way so as all inputs to the control unit are only the correct input data. The contact address of the data information is determined in the data matrix by means of a combination of the corresponding line and column. These addresses are given in the hexadecimal system [4].

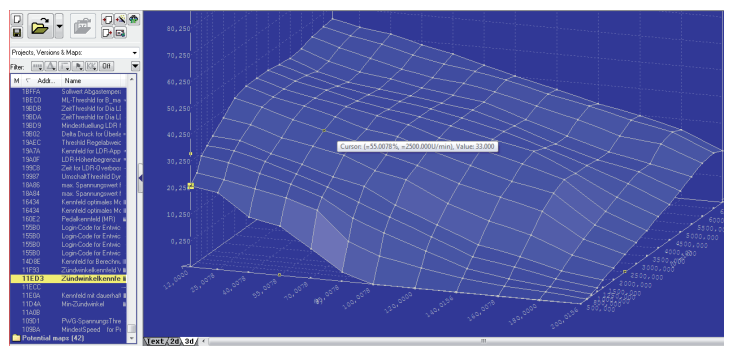

Fig. 3: Active 3D ignition data field.

A very important condition for adjustment of the control program is keeping of the control summation level, i.e. the so-called checksum. This control summation serves predominately for a control of the saved data integrity in the memory EPROM/ EEPROM. The algorithm controls the correctness of the used data. The producers of the control units are using the checksum also for the safety pur- poses of external protection of the data fields. The advanced user ambient of the editing programs enables to perform calculation of the checksum corrections in order the final value corresponds to the requirements of the control unit software. The original numerical values of the control software represent not only the concrete values (e.g. values of the injection process), but also they enable to realise the following calculation process of the real values (Fig. 3). During the data transformation it is necessary to know the computational algorithm, which is included in the computer code [5].

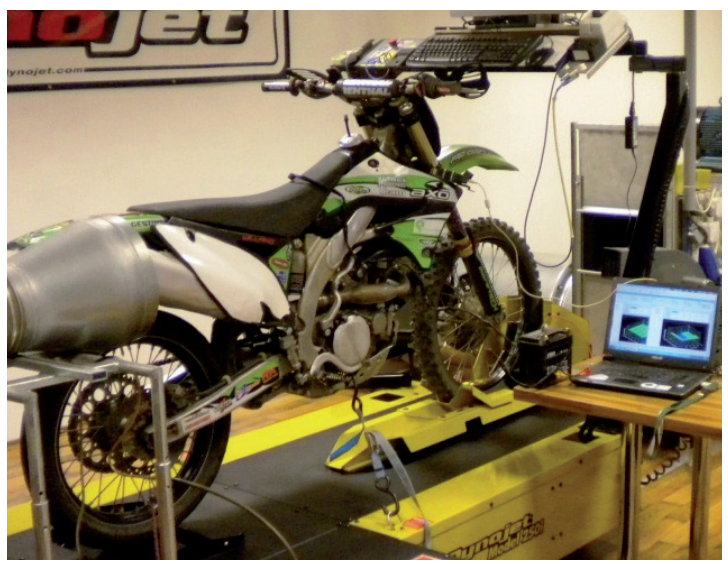

Fig. 4: Downloading ECU data of motorcycle KAWASAKI KX 450F.

It is a necessary task to assembly the optimal data fields in order to improve the power output parameters. There is created a complex system of interrelations among the individual data fields and due this fact they are influencing each other. Considerable is also a relation between the input and output parameters of the motor-management. The control unit enables to perform corrections of the above-mentioned mutual interrelations and to modify the output values (Fig. 4) [6].

The engine management is able to adjust the output values according to the mutual interrelations that are presented in the two-dimensional or three-dimensional data fields. These data fields are called the data maps. In order to increase the power output parameters together with increasing of the combustion process efficiency the most important data maps are as follows:

- data fields of the fuel injection,

- data fields of the spark advance,

- data fields of the charging pressure regulation, - data fields of the supplementary systems (EGR, 
NOS etc.),

data fields of the sensors and active components.

\section{Results and Discussion \\ 3.1 Verification the correctness of adjustment engine management}

To verify the proper functionality of the modified engine management system is a necessary tool that allows to check correctness. For this purpose was designed KX Racing Software from KEIHIN CORPORATION (Fig.5).

This system allows to control the activities of the following operating parameters:

- engine speed (1),

- TPS throttle position (2),

vacuum in intake pipe (3),

- temperature of cooling liquid (4),

- temperature of intake air (5),

- condition of advance ignition (6),

- condition of fuel injection (7),

- transmission gear (8),

- power status (9).

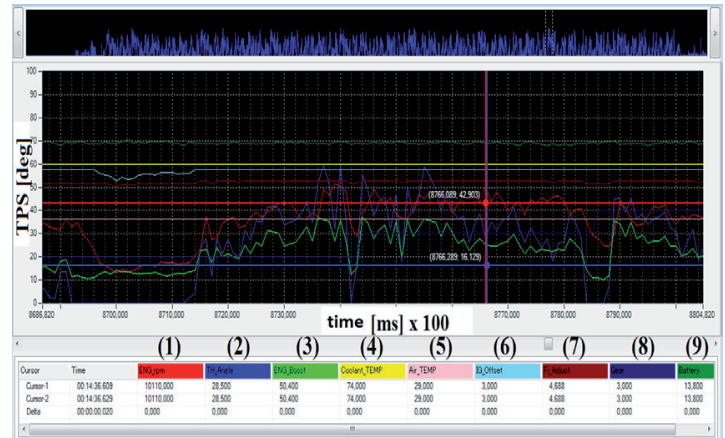

Fig. 5: Recording of operating parameters on racing track.

Determination of parameters of power and torque is decisive element in the editing engine management. Traceability of effect modification of data fields is important in assessing the accuracy of modifications engine management. Any major modification of the control unit of activity produces adequate changes, and therefore the best way to capture the changes manifested measurement characteristics on the power of the combustion engine dynamometer. To verify the accuracy of editing data fields injection and ignition advance roller dynamometer was used DYNOJET 250i in society EUROTANK RACING Betliar. This is one of the most advanced dynamometers used in determining performance parameters of motorcycles.
Verification of the impact of using individual fuel maps and ignition advance on a roller dynamometer confirmed the performance gains of $12 \%$ and an increase in torque by $10 \%$ (Fig. 6). Engine after adjusting disposed of greater flexibility and improved acceleration.

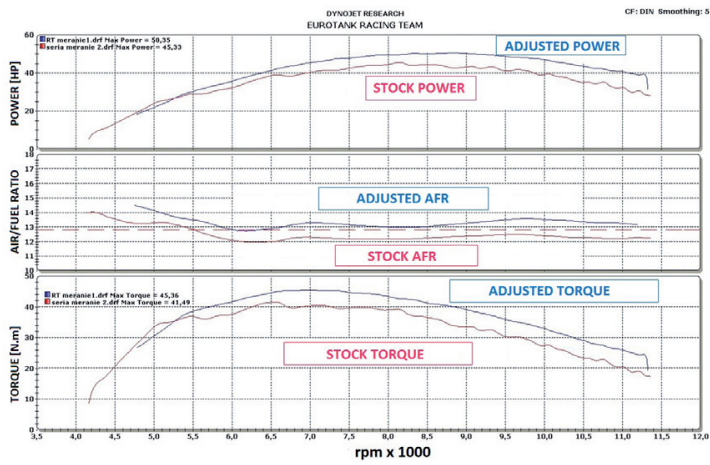

Fig. 6: Output characteristics before and after modification of engine management.

\section{Conclusion}

The modern control systems of the four-stroke spark-ignition engine require a continual distribution of the correct operational information. Therefore it is necessary to control correctness of these data all the time. The specialised modification software WinOLS 1.721 is developed just for this purpose. It enables recording of the data fields obtained from the sensing elements and following editing of them. The correct editing of the data field contributes to a faster and more correct distribution of the sensed values. This methodology increases efficiency of the motor-management operation of the racing sparkignition engine.

\section{Acknowledge}

At the present time the problem is solved in the framework projects "VEGA 1/0277/13 New Methods of Efficiency Increasing and Emission Reductions for Driving Unit of Transport Vehicle Using Innovation of Main Components and Consequent Optimisation of Production Process of them with Consideration of Possible Production and Operation Risk" and "VEGA 1/0356/11 Innovative processes in construction of driving units applied in transport means, machines and optimisation of material flows and logistics in order to save energy and to increase reliability with regard to application purposes in the practice". 


\section{References}

[1] BIGOŠ, P., - PUŠKÁR, M.: Increasing of power output of racing motorcycle engine using of exhaust system optimisation / Peter Bigoš, Michal Puškár - 2011. In: Acta Mechanica Slovaca. Roč. 15, č. 1 (2011), s. 70-77. - ISSN 1335-2393.

[2] BIGOŠ, P.; PUŠKÁR, M.: Engine output increase of two-stroke combustion with exhaust system optimization, In: Strojarstvo. Vol. 50, no. 2 (2008), p. 69-76. , ISSN 0562-1887.

[3] PUŠKÁR, M.; BIGOŠ, P.; BALÁŽIKOVÁ, M.; PEŤKOVÁ, V.: The measurement method solving the problems of engine output characteristics caused by change in atmospheric condition on the principle of the theory of optimal temperature range of exhaust system, Measurement 2013, Vol. 46, no. 1 (2013), p. 467-475, ISSN 0263-2241.

[4] PUŠKÁR, M.; BIGOŠ, P.; PUŠKÁROVÁ, P.: Accurate measurements of output characteristics and detonations of motorbike high-speed racing engine and their optimization at actual atmospheric conditions and combusted mixture composition, Measurement 2012, Vol. 45, no. 5 (2012), p. 1067-1076, ISSN 0263-2241.

[5] PUŠKÁR, M.; BIGOŠ, P.: Method for accurate measurements of detonations in motorbike high speed racing engine, Measurement 2012, Vol. 45, no. 3 (2012), p. 529-534, ISSN 0263-2241.

[6] PUŠKÁR, M.; BIGOŠ, P.: Output Performance Increase of Twostroke Combustion Engine with Detonation Combustion Optimization, In:Strojarstvo 2010: Vol. 52, no. 5 (2010), p. 577-587, ISSN 0562-1887. 